\title{
Author Correction: Health and sustainability in post-pandemic economic policies
}

Carla Guerriero (D), Andy Haines (1) and Marco Pagano

Correction to: Nature Sustainability https://doi.org/10.1038/s41893-020-0563-0, published online 8 June 2020.

In the version of this Comment originally published, in the last sentence of the penultimate paragraph, the citation of reference 19 was incorrect and should have been a citation of reference 8 .

The sentence 'Some investments may indeed qualify both on environmental and health criteria: for example, renewable energy technologies yield a double environmental and health benefit, with the potential to prevent about 430,000 premature deaths annually in the EU from air pollution attributable to burning fossil fuels ${ }^{19}$.' has been changed to:

'Some investments may indeed qualify both on environmental and health criteria: for example, renewable energy technologies yield a double environmental and health benefit, with the potential to prevent about 430,000 premature deaths annually in the EU from air pollution attributable to burning fossil fuels ${ }^{8}$.'

This has now been corrected.

Published online: 17 June 2020

https://doi.org/10.1038/s41893-020-0575-9

(C) Springer Nature Limited 2020 